\title{
Валидация методики определения аскорбиновой кислоты методом высокоэффективной тонкослойной хроматографии
}

\author{
Тринеева О.В., Сафонова Е.Ф., Сливкин А.И. \\ ФГБОУ ВО «Воронежский государственный университет», Воронеж
}

Поступила в редакцию 4.05.2017 г.

\begin{abstract}
Проведена валидация разработанной методики идентификации и количественного определения аскорбиновой кислоты методом высокоэффективной тонкослойной хроматографии по показателям предел обнаружения, специфичность, линейность, эффективность и повторяемость. Разработанный способ определения аскорбиновой кислоты был апробирован на лекарственном растительном сырье листьев крапивы двудомной и плодов облепихи крушиновидной. Методика может быть использована в контроле качества субстанции, монокомпонентных и комплексных препаратов, содержащих витамин С, лекарственного растительного сырья, биологически активных добавок, премиксов, изделий пищевой и косметологической промышленностей.
\end{abstract}

Ключевые слова: аскорбиновая кислота, высокоэффективная тонкослойная хроматография, валидация.

\section{Validation of methods for determining ascorbic acid by high performance thin layer chromatography}

\author{
Trineeva O.V., Safonova E.F., Slivkin A.I. \\ Voronezh state university, Voronezh
}

For the identification and quantitative determination of ascorbic acid chromatographic methods are widely used recently. TLC, having all the advantages of chromatographic methods, is widely used in view of their rapidity, availability of sufficient sensitivity, selectivity and ease of the analysis. However, using the TLC method in pharmaceutical analysis is limited primarily, only the establishment of a purity of drugs and substances of ordinary dosage forms. The authors have developed and patented method of determination of ascorbic acid by thin layer chromatography sorbent that can be used as a quality control substance complex and monocomponent preparations or plant facilities of dietary supplements, premixes, cosmetic products and food industries. This technique makes it possible not only to obtain the chromatograms clear ascorbic acid zone round shape with an $\mathrm{R}_{\mathrm{f}}$ value of the optimal value, but also to carry out the separation of complex mixtures of vitamin $\mathrm{C}$ with other biologically active substances, as well as to evaluate its quantitative content in the samples. However, in order that the proposed analytical procedure has taken a worthy place in the quality assurance system that is guaranteed authentic and accurate analysis results, further procedure for its validation (qualification) was carried out. From a practical point of view during the validation process of the development of new techniques, you can quickly identify their shortcomings and in the early stages significantly improve technique. Practice validation experiments gives understanding of the techniques and awareness of the need for strict observance of its parameters. As a result, during the subsequent operation of a validated method significantly reduces the likelihood of errors. The aim of the study was to validate the developed method of identification and quantitative determination of ascorbic acid by high performance thin layer chromatography sorbent. Spend validation of developed methods of identification and quantitative determination of ascorbic acid by high performance thin layer chromatography in terms of detection limit, specificity, linearity, efficiency, and repeatability. The technique can be used in quality control substance, monocomponent and complex preparations containing ascorbic acid, medicinal plants, food supplements, premixes, products of the food and cosmetic industries.

Keywords: ascorbic acid, high-performance thin-layer chromatography, validation. 


\section{Введение}

Для идентификации и количественного определения аскорбиновой кислоты (АК) в последнее время широко применяются хроматографические методы, важнейшим из которых является ВЭЖХ [1-4]. ТСХ, обладая всеми преимуществами хроматографических методов, находит широкое применение в виду своей экспрессности, доступности, достаточной чувствительности, селективности и простоте выполнения анализа [5]. Однако, использование метода ТCX в фармацевтическом анализе ограничивается, в основном, только установлением доброкачественности лекарственных веществ в субстанциях и простых лекарственных формах. Авторами разработана и запатентована методика [6] определения АК методом хроматографии в тонком слое сорбента, которая может быть использована в контроле качества как субстанции, монокомпонентных и комплексных препаратов, так и растительных объектов, биологически активных добавок, премиксов, изделий пищевой и косметологической промышленностей. Данная методика позволяет не только получать на хроматограммах четкие зоны АК округлой формы с оптимальным значением величины $\mathrm{R}_{\mathrm{f}}$, но и проводить разделение сложных смесей $\mathrm{AK}$ с другими биологически активными веществами, а также оценивать ее количественное содержание в образцах.

Целью настоящей работы являлась валидация разработанной методики идентификации и количественного определения АК методом высокоэффективной хроматографии в тонком слое сорбента.

\section{Эксперимент}

В работе использовали 0.2\% водный раствор АК (ЗАО Вектон, СПб, Россия). Исследуемые растворы АК объемом 2 мкл наносили при помощи микрошприца (МШ-10, Россия) на стартовую линию хроматографических пластин марок «Sorbfil» ПТСХ-АФ-А и ПТСХ-П-В (высокоэффективные) размером 10×10 см (тип сорбента: силикагель СТХ-1А, СТХ-1ВЭ; зернение: 5-17 мкм, 8-12 мкм; толщина слоя: 90-120 мкм, 80-100 мкм соответственно; связующее: силиказоль). В работе использовали растворители марки х.ч. (ЗАО «Вектон», СПб, Россия). Зоны АК на хроматограммах обнаруживали способом опрыскивания хроматограмм раствором обнаруживающего реагента $(0.2 \%$ спиртовый раствор 2,6-дихлорфенолиндофенолята натрия, ЗАО «Вектон», СПб, Россия) с помощью пульверизатора (spraying).

При разработке методики были выбраны и теоретически обоснованы оптимальные условия хроматографирования АК в тонком слое сорбента: сорбент - силикагелевые пластинки марки «Sorbfil» $5 \times 10$ см с алюминиевой ПТСХ-АФ-А или полимерной ПТСХ-П-В подложками; элюент - этилацетат-ледяная уксусная кислота (85:15); проявитель - 0.2\% спиртовый раствор 2,6-дихлорфенолиндофенолята натрия; оптимальный объем пробы - 2 мкл спиртового раствора с содержанием АК 2 мг/мл; время насыщения камеры парами элюента - 20 мин; время элюирования -35 мин; время выдерживания пластинки в термостате после проявления при $\mathrm{t}^{\circ} \geq 80{ }^{\circ} \mathrm{C}-$ 3-5 минут [6].

\section{Обсуждение результатов}

Для визуальной оценки хроматографических зон пластину после элюирования необходимо обработать каким-либо проявителем. Выбор проявителя осуществляли с учетом таких требований как специфичность, чувствительность, доступность, высокое 
качество получаемой картины, а также контрастность хроматографических зон и фона, что может позволить проводить дальнейший количественный анализ с применением сканирующих устройств. Пределы обнаружения пятен АК с помощью выбранных реагентов приведены в табл. 1. 2, 6-дихлорфенолиндофенолят натрия является специфическим фармакопейным реактивом, используемом в качественном и количественном анализе АК в присутствии других компонентов, что явилось критерием выбора.

Таблица 1. Характеристика детектирующих реагентов для определения АК методом TCX

\begin{tabular}{|c|c|c|c|c|}
\hline $\begin{array}{l}\text { № } \\
\Pi / \Pi\end{array}$ & $\begin{array}{l}\text { Детектирующий } \\
\text { реагент }\end{array}$ & $\begin{array}{c}\text { Окрашивание } \\
\text { хроматографиче- } \\
\text { ских зон } \\
\end{array}$ & $\begin{array}{r}\text { Предел оп- } \\
\text { ределения, г }\end{array}$ & $\begin{array}{l}\text { Специфич- } \\
\text { ность }\end{array}$ \\
\hline 1 & $\begin{array}{c}5 \text { \% спиртовый } \\
\text { раствор фосфорно- } \\
\text { молибденовой кислоты } \\
\text { (ФМК) }\end{array}$ & $\begin{array}{l}\text { Синее на желто- } \\
\text { зеленом фоне }\end{array}$ & $4 \cdot 10^{-7}$ & - \\
\hline 2 & УФ-свет (254 нм) & $\begin{array}{c}\text { Ярко-малиновое } \\
\text { свечение на белом } \\
\text { фоне } \\
\end{array}$ & $4 \cdot 10^{-7}$ & - \\
\hline 3 & $\begin{array}{c}0.2 \% \text { спиртовый } \\
\text { раствор 2,6- } \\
\text { дихлорфенолиндофенолята } \\
\text { натрия }\end{array}$ & $\begin{array}{c}\text { Белое на розовом } \\
\text { фоне }\end{array}$ & $2 \cdot 10^{-6}$ & + \\
\hline 4 & $\begin{array}{c}0.2 \% \text { спиртовый } \\
\text { раствор бромкрезолового зе- } \\
\text { леного }\end{array}$ & Не проявляет & - & - \\
\hline 5 & \begin{tabular}{|c|}
$0.2 \%$ спиртовый \\
раствор бромфенолового сине- \\
го \\
\end{tabular} & Не проявляет & - & - \\
\hline 6 & $\begin{array}{c}0.01 \text { М раствор нитрата сереб- } \\
\text { ра }\end{array}$ & $\begin{array}{l}\text { Темно-серое на бе- } \\
\text { лом фоне }\end{array}$ & $1 \cdot 10^{-6}$ & - \\
\hline
\end{tabular}

В эксперименте изучено шестнадцать типов элюирующих систем с различными значениями полярности (табл. 2). Для каждой элюирующей системы рассчитаны полярность (Р’) системы по Снайдеру и величина $\left(\mathrm{R}_{f}\right)$.

Таблица 2. Хроматографические параметры АК в различных элюирующих системах

\begin{tabular}{|c|c|c|c|c|c|}
\hline № ח/п & Элюент & $\mathrm{R}_{\mathrm{f}}$ & $\mathrm{H}, \mathrm{MM}$ & $\mathrm{N}$ & $\mathrm{P}^{\prime}$ \\
\hline 1 & 2 & 3 & 4 & 5 & 6 \\
\hline 1 & Хлороформ & $0.01 \pm 0.001$ & 0 & - & 4.40 \\
\hline 2 & Бензол & $0.01 \pm 0.001$ & 0 & - & 3.00 \\
\hline 3 & Этиловый эфир-гексан (1:1) & $0.01 \pm 0.001$ & 0 & - & 1.45 \\
\hline 4 & $\begin{array}{c}\text { н-бутанол-муравьиная кислота-вода } \\
(25: 2.5: 29.7) \\
\end{array}$ & $0.66 \pm 0.010$ & 0.46 & 177 & 6.70 \\
\hline 5 & $\begin{array}{c}\text { н-бутанол-муравьиная кислота-вода } \\
(5: 0.5: 2)\end{array}$ & $0.63 \pm 0.010$ & 0.48 & 173 & 5.47 \\
\hline 6 & $\begin{array}{c}\text { н-бутанол-уксусная кислота-вода } \\
(4: 1: 5) \\
\end{array}$ & $0.57 \pm 0.020$ & 0.53 & 154 & 6.68 \\
\hline 7 & $\begin{array}{c}\text { Этанол-конц. раствор аммиака } \\
(16: 4.5)\end{array}$ & $0.69 \pm 0.010$ & 0.18 & 400 & - \\
\hline 8 & н-пропанол-раствор аммиака (6:4) & $0.92 \pm 0.020$ & 1.19 & 62 & - \\
\hline
\end{tabular}




\begin{tabular}{|c|c|c|c|c|c|}
\hline 1 & 2 & 3 & 4 & 5 & 6 \\
\hline 9 & $\begin{array}{c}\text { этилацетат-муравьиная кислота-вода } \\
(3: 1: 1)\end{array}$ & $0.63 \pm 0.010$ & 0.18 & 439 & 5.78 \\
\hline 10 & $\begin{array}{c}\text { этилацетат-уксусная кислота- } \\
\text { муравьиная кислота-вода } \\
(100: 11: 11: 25)\end{array}$ & $0.67 \pm 0.010$ & 0.29 & 282 & 5.44 \\
\hline 11 & этилацетат-уксусная кислота (80:20) & $0.54 \pm 0.010$ & 0.36 & 247 & 4.68 \\
\hline 12 & этилацетат-уксусная кислота (85:15) & $0.42 \pm 0.010$ & 0.10 & 767 & 4.59 \\
\hline 13 & этилацетат-уксусная кислота (90:10) & $0.37 \pm 0.010$ & 0.13 & 664 & 4.49 \\
\hline 14 & этилацетат-уксусная кислота (95:5) & $0.26 \pm 0.010$ & 0.17 & 521 & 4.40 \\
\hline 15 & $\begin{array}{c}\text { Ацетон-метанол-уксусная кислота } \\
(3: 1: 1)\end{array}$ & $0.53 \pm 0.010$ & 0.20 & 443 & 5.80 \\
\hline 16 & $\begin{array}{c}\text { Ацетон-толуол-муравьиная кислота } \\
(6: 3: 1)\end{array}$ & $0.99 \pm 0.010$ & 0.522 & 172 & 4.63 \\
\hline
\end{tabular}

На хроматограммах для каждой элюирующей системы были рассчитаны также параметры эффективности хроматографического процесса, такие как высота, эквивалентная теоретической тарелке $(\mathrm{H})$; число теоретических тарелок $(\mathrm{N})$ [7]. Данные табл. 2 показывают, что наибольшая эффективность хроматографического процесса, согласно значениям величин $\mathrm{N}$ и $\mathrm{H}$, наблюдалась в системах №7,9,12-15, а наименьшая - в системе № 8. Системы №1-3 являются неэффективными. Параметры $\mathrm{N}$ и Н взаимосвязаны между собой нелинейной обратно пропорциональной зависимостью. Оптимальные величины $\mathrm{R}_{\mathrm{f}}$ достигнуты в системах №6,11-15. Хроматографирование можно проводить в системах №12-15. Системы №12-14 предлагаются впервые. Для количественной обработки хроматограмм методом компьютерного сканирования целесообразно применять систему № 12 , так как лучшие значения $\mathrm{R}_{\mathrm{f}}$, $\mathrm{H}, \mathrm{N}$, а также качество хроматографических зон было достигнуто в данной системе (табл. 2).

Сразу же после проявления хроматографических зон, пластины сканируют с помощью планшетного сканера EPSON PERFECTION 2480 PHOTO (разрешение не менее $300 \mathrm{dpi}$ ), а полученные изображения (рис. 1) обрабатывают компьютерной программой «Sorbfil Videodensitometer» (Россия). Установлена линейная зависимость между содержанием АК и площадью хроматографической зоны в диапазоне изучаемых концентраций.

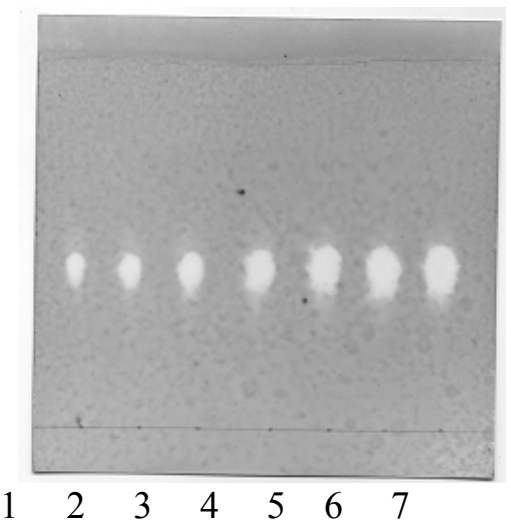

Рис. 1. Калибровочная хроматограмма с серией стандартных растворов (0.150.45\%) АК: 1 - 3 мкг; 2 - 4 мкг; 3 -5 мкг; 4 - 6 мкг; 5 - 7 мкг; 6 - 8 мкг; 7 - 9 мкг

Разработанный способ идентификации и количественного определения АК был апробирован на лекарственном растительном сырье (ЛРС) листьев крапивы 
двудомной и плодов облепихи крушиновидной, которые, по данным литературы, богаты витамином С. Однако в НД определение АК не предусмотрено.

Извлечение из исследуемого сырья готовили по общей фармакопейной статье ГФ ХІІІ изд. «Настои и отвары» [9]. Полученные вытяжки хроматографировали восходящим способом в условиях разработанной методики. Результаты количественного определения АК в извлечениях представлены в табл. 3.

Таблица 3. Результаты количественного определения АК в извлечениях из ЛРС

\begin{tabular}{|c|c|c|c|}
\hline \multirow{2}{*}{ № п/п } & \multirow{2}{*}{ ЛРС } & \multicolumn{2}{|c|}{ Методика ВЭТСХ } \\
\cline { 3 - 4 } & & $\mathrm{R}_{\mathrm{f}}$ & Содержание АК, \% \\
\hline 1 & Листья крапивы двудомной & 0.43 & $0.053 \pm 0.015$ \\
\hline 2 & Плоды облепихи крушиновидной & 0.42 & $0.047 \pm 0.001$ \\
\hline
\end{tabular}

Однако для того, чтобы предлагаемая аналитическая методика заняла достойное место в системе обеспечения качества, т.е. гарантировала достоверные и точные результаты анализа, дополнительно была проведена процедура ее валидации (аттестации). С практической точки зрения при проведении валидации в процессе разработки новых методик можно своевременно выявить их недостатки и на ранних стадиях существенно улучшить методику. Практика валидационных экспериментов дает понимание сути методики и осознание необходимости строгого соблюдения ее параметров. В результате при последующей эксплуатации валидированной методики значительно снижается вероятность ошибок.

Проведена валидация разработанной методики по показателям предел обнаружения, специфичность, эффективность, линейность и повторяемость (внутри- и межлабораторная).

Чувствительность методики устанавливали по величине обнаруживаемого минимума вещества в пятне, который визуально проявляется после детектирования. Предел обнаружения с помощью выбранного реагента составил $2 \cdot 10^{-6}$ г, что сопоставимо по чувствительности с определением витамина методом ВЭЖХ.

Специфичность определяли по величине $\mathrm{R}_{\mathrm{f}}$ пятна контрольного трека, которое должно соответствовать $\mathrm{R}_{\mathrm{f}}$ пятна стандартного образца $\left(\mathrm{R}_{\mathrm{f}}=0.42 \pm 0.01\right)$. На треке контрольного образца визуально обнаруживалось пятно, которое по интенсивности окраски и величине $\mathrm{R}_{\mathrm{f}}$ соответствовало пятну АК на треке стандартного образца (рис. 2 и 3 ).

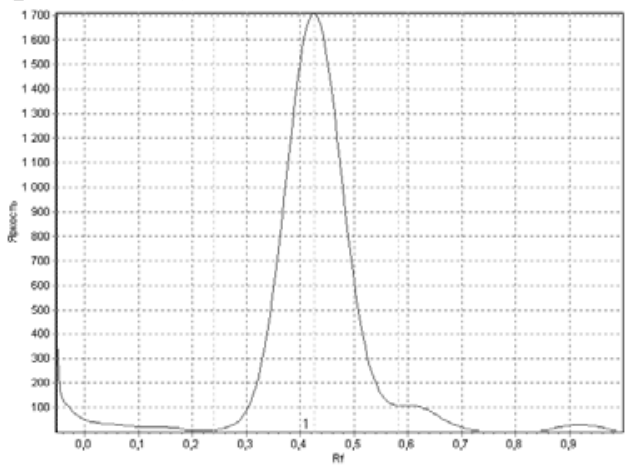

Рис. 2. Аналоговая кривая стандартного раствора АК

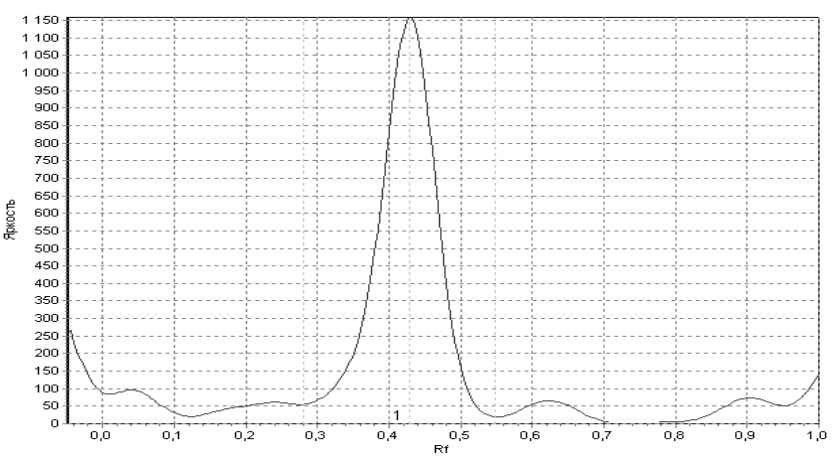

Рис. 3. Аналоговая кривая извлечения из листьев крапивы двудомной

Эффективность пластинки определяли по числу теоретических тарелок хроматографических зон стандартных образцов и коэффициентам асимметрии пиков на хроматограммах. Данный показатель составил - 767 (табл. 2), что соответствует допустимому критерию приемлемости (не менее 500). Коэффициенты асимметрии по- 
лученных пиков (рис. 2 и 3), рассчитанные при помощи компьютерной программы «Sorbfil Videodensitometer» представлены в табл. 4.

Таблица 4. Коэффициенты асимметрии пиков на хроматограммах

\begin{tabular}{|c|c|c|}
\hline № п/п & Хроматограмма & As \\
\hline 1 & Калибровочная хроматограмма серии стандартных растворов АК & $0.80-0.96$ \\
\hline 3 & Хроматограмма извлечения из листьев крапивы двудомной & $0.83-0.94$ \\
\hline 4 & Хроматограмма извлечения из плодов облепихи крушиновидной & $1.15-1.16$ \\
\hline
\end{tabular}

Искажение формы пика не сильно влияет на качество разделения в ТСХ при коэффициенте асимметрии, не превышающем 2-2.5 [8].

При оценке линейности методики, критерием приемлемости служит коэффициент корреляции (не менее 0.995). Полученная величина коэффициента корреляции 0.9941 (рис. 4) позволяет утверждать о наличии достаточно жесткой линейной зависимости площади хроматографической зоны от концентрации [8].

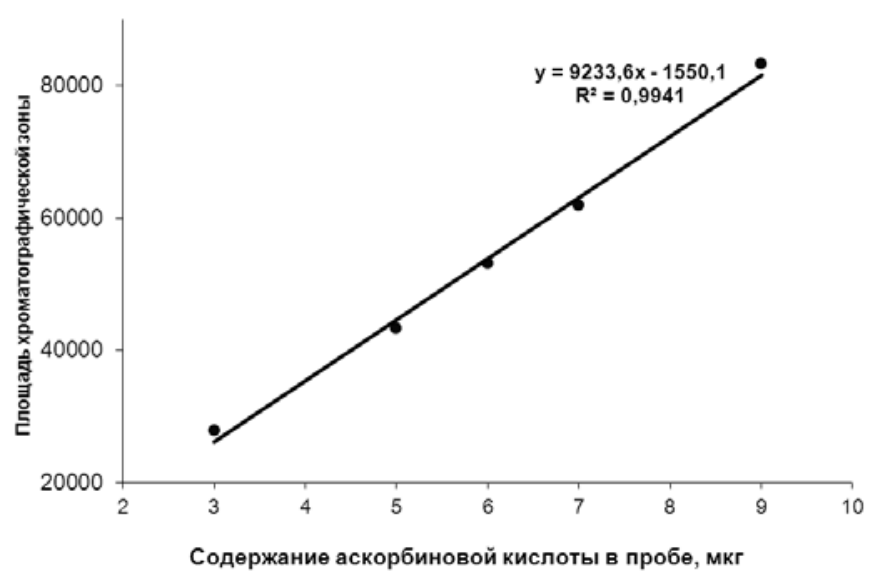

Рис. 4. Зависимость площади хроматографических зон от содержания АК в пробе (область концентраций 0.15-0.45\%)

Для определения внутрилабораторной повторяемости методики хроматографирование было выполнено в шести повторностях для стандартных образцов АК. Межлабораторную воспроизводимость определяли, используя хроматографические пластинки различных типов [8] (табл. 5). Результаты, полученные при статистической обработке, достоверны при доверительной вероятности 95\%, вычисленные значения RSD не превышают критериев приемлемости - 5\%, что свидетельствует о прецизионности методики в условиях повторяемости (табл. 5). Метрологическая оценка предложенной методики на примере плодов облепихи крушиновидной представлена в табл. 6.

Таблица 5.Результаты определения повторяемости методики

\begin{tabular}{|c|c|c|}
\hline \multirow{2}{*}{ Образец } & Значение $\mathrm{R}_{\mathrm{f}}$ стандартных образцов аскорбиновой кислоты \\
\cline { 2 - 3 } & ПТСХ-АФ-А & ПТСХ-П-В \\
\hline 1 & 2 & 3 \\
\hline 1 & 0.410 & 0.410 \\
\hline 2 & 0.420 & 0.420 \\
\hline 3 & 0.430 & 0.420 \\
\hline 4 & 0.430 & 0.420 \\
\hline 5 & 0.430 & 0.440 \\
\hline 6 & 0.430 & 0.460 \\
\hline
\end{tabular}




\begin{tabular}{|c|c|c|}
\hline 1 & 2 & 3 \\
\hline $\mathrm{X}_{\mathrm{cp}}$ & 0.425 & 0.428 \\
\hline $\mathrm{RSD}, \%$ & 1.896 & 1.840 \\
\hline $\mathrm{SD} \%$ & 0.81 & 4.30 \\
\hline
\end{tabular}

Таблица 6. Метрологическая характеристика метода анализа (P=95\%; n=4)

\begin{tabular}{|c|c|c|c|c|c|c|c|c|c|}
\hline $\mathrm{f}$ & $\mathrm{x}_{\mathrm{cp}}$ & $\mathrm{S}^{2}$ & $\mathrm{~S}$ & $\mathrm{Sx}_{\mathrm{cp}}$ & $\mathrm{t}(\mathrm{P}, \mathrm{t})$ & $\Delta \mathrm{x}$ & $\Delta \mathrm{x}_{\mathrm{cp}}$ & $\varepsilon_{\mathrm{cp}}, \%$ & $\varepsilon, \%$ \\
\hline 3 & 0.0468 & 0.0000006 & 0.00077 & 0.00039 & 3.18 & 0.0025 & 0.00123 & 2.62 & 5.24 \\
\hline
\end{tabular}

\section{Заключение}

Проведена валидация разработанной методики идентификации и количественного определения АК методом высокоэффективной тонкослойной хроматографии по показателям предел обнаружения, специфичность, линейность, эффективность и повторяемость. Методика может быть использована в контроле качества субстанции, монокомпонентных и комплексных препаратов, содержащих АК, лекарственного растительного сырья, биологически активных добавок, премиксов, изделий пищевой и косметологической промышленностей.

\section{Список литературы}

1. Борисова Д.А., Попов Д.М. // Фармаџия. № 3. 2013. С. 22-24.

2. Попова Т.С., Потанина О.Г. // Фармация. № 2. 2013. C. 11-13.

3. ГОСТ 24556-89. Продукты переработки плодов и овощей. Методы определения витамина С. - М. ИПК Изд-во стандартов. 1989. Введ. 01.01.1990. $11 \mathrm{c.}$

4. ГОСТ Р 53693-2009. Продукция соковая. Определение аскорбиновой кислоты методом высокоэффективной жидкостной хроматографии. М. Стандартинформ. 2010. Введ. 01.01.2011. $16 \mathrm{c.}$

5. Василенко Е.А., Мезенова Т.Д., Попова О.И., Дмитриев А.Б. // Фармация. № 1. 2013. C. 16-19.

\section{References}

1. Borisova D.A., Popov D.M., Farmatsiya, 2013, No 3, pp. 22-24.

2. Popova T.S., Potanina O.G., Farmatsiya, 2013, No 2, pp. 11-13.

3 . GOST 24556-89. Produkty pererabotki plodov i ovoshchei. Metody opredeleniya vitamina C. - M.: IPK Izd-vo standartov, 1989. Vved. $01.01 .1990,11 \mathrm{p}$.

4. GOST R 53693-2009. Produktsiya sokovaya. Opredelenie askorbinovoi kisloty metodom vysokoeffektivnoi zhidkostnoi khromatografii. M., Standartinform, 2010. Vved. 01.01.2011, 16 p.
6. Тринеева О.В. Патент РФ. №2581456. 2014.

7. Гейсс Ф. Основы тонкослойной хроматографии. М. Мир. 1999. 405 с.

8. Гаврилин М.В., Сенченко С.П. Валидация аналитических методик. Пятигорск. ПГФА. 2008. 37 с.

9. Государственная Фармакопея Российской Федерации XIII изд. ОФС «Настои и отвары». Режим доступа: http://www.rosminzdrav.ru/ministry/61/11/mate rialy-po-deyatelnosti-deparatamenta/ stranitsa856/spisok-obschih-farmakopeynyh-statey. (дата обращения 11.10.2015).

5. Vasilenko E.A., Mezenova T.D., Popova O.I., Dmitriev A.B., Farmatsiya, 2013, No 1, pp. 16-19.

6. Trineeva O.V., Patent RU № 2581456, 2014.

7. Geiss F. Osnovy tonkosloinoi khromatografii. M., Mir, 1999, 405 p.

8. Gavrilin M.V., Senchenko S.P. Validatsiya analiticheskikh metodik. Pyatigorsk: PGFA, 2008, 37 p.

9. Gosudarstvennaya Farmakopeya Rossiiskoi Federatsii XIII izd. OFS «Nastoi i otvary».(http://www.rosminzdrav.ru/ministry/61/1 1/materialy-po-deyatelnosti-deparatamenta/ 
stranitsa-856/spisok-obschih-farmakopeynyh-

Тринеева Ольга Валерьевна - доцент кафедры фармацевтической химии и фармацевтической технологии фармацевтического факультета, к.фарм.н., Воронежский государственный университет, Воронеж

Сафонова Елена Федоровна - зав. кафедрой фармации, к.х.н., Воронежский государственный университет, Воронеж

Сливкин Алексей Иванович - профессор, зав.кафедрой фармацевтической химии и фармацевтической технологии, декан фармацевтического факультета, д.фарм.н., Воронежский государственный университет, Воронеж statey). (data obrashcheniya 11.10.2015).

Trineeva Olga V. - Ph.D. (pharmaceutical hemistry), Associate Professor, Department of Pharmaceutical Chemistry and Pharmaceutical Technology Faculty of Pharmacy, Voronezh State University, Voronezh, e-mail: $\underline{\text { Trinee- }}$ vaOV@mail.ru

Safonova Elena F. - Ph.D. (pharmaceutical chemistry), Associate Professor, Head. the Department of Pharmacy, Voronezh State University, Voronezh, e-mail: safonova@pharmvsu.ru

Slivkin Alexei I. - prof., grand Ph.D (pharmaceutical chemistry), Head. the Department of Pharmaceutical Chemistry and Pharmaceutical Technology, Dean of the Faculty of Pharmacy, Voronezh State University, Voronezh. e-mail: slivkin@pharmvsu.ru 